\title{
DETECTING FATIGUE IN THE WORKPLACE
}

\author{
Tyler D. Asher and Ian Mc Andrew \\ Capitol Technology University, Laurel, Maryland, USA
}

\begin{abstract}
This paper evaluates current case studies on how companies within the United States detect fatigue in the workplace, and how it is addressed through training. Workplace fatigue is one of the highest risks for safety sensitive positions and presents an imminent danger to employees and their coworkers. Corporations have developed ways to observe for fatigue, lack of training and acknowledgement many cases of workplace fatigue go under the radar and can eventually lead to an incident. Why is there such an influx of fatigue related incidents, and why are companies not better at recognizing the signs and symptoms of workplace fatigue? The intention is to suggest and recommend safe work practices for workers to combat fatigue before, during and after fatigue has set in. Corrective measures would include proper training, a well-balanced diet, and proper rest between each shift. This paper will also review sleep/wake cycles that moderate the human body and the way we mitigate workplace fatigue.
\end{abstract}

\section{KEYWORDS}

Fatigue; Alertness; Emotional Stability; Mental Ability; Physical Ability; Circadian Rhythm

\section{INTRODUCTION}

Understanding how fatigue impacts a worker is difficult to substantiate, but ways to detect fatigue is something American safety professionals have been working on resolving since the OSH Act came into force in 1970 . Due to fatigue being so hard to monitor, most safety professionals have a hard time verifying it as a known hazard. Research shows that fatigue can be identified in four key areas of workplace performance: alertness, emotional stability, mental abilities, and physical abilities (Sawatzky, 2017). In many industries, fatigue is an underlying condition that goes undetected and is the cause of many preventable incidents. In 2019, roughly 100,000 traffic incidents were caused by fatigued drivers. Of those, 1,550 resulted in fatalities, and there were many more serious incidents (NSC, 2019). Significant research and evaluations of fatigue have been published, the majority of which are automotive driver focused, and this has been used by many as a benchmark. In this research, the application in construction is the principal focus. Construction companies have developed ways to observe for fatigue, lack of training and acknowledgement many cases of workplace fatigue go under the radar and can eventually lead to an incident. In most cases it is not identified at fatigue until after the incident occurs and its discovered in the root cause analysis. The Occupational Safety \& Health Administration (OSHA) and the National Safety Council (NSC) have conducted similar research and work in ways to mitigate fatigue and how to properly identify when someone is experiencing fatigue.

\section{THEORY}

Fatigue is a physiological trait of the human body. it examines different avenues of fatigue in the workplace, must start with human traits that can generate fatigue and tiredness in the human body. The reasons why fatigue impacts the workforce and the work environment of so many Americans must be explored. Research conducted by author Susan Sawatzky shows that lack of 
alertness is the beginning of an impacted employee who is beginning to experience fatigue, mentally and physically. Another type of fatigue is that experienced by employees who are on call. This research has been conducted many times with similar results, and typically end up with turnover (Karasek, 1998). Depending on the workload, work can cause physical fatigue that can lead to emotional stress (Sholihah, 2014).

\section{HYPOTHESIS}

Null Hypothesis:

Higher levels of training will increase the awareness of fatigue. (one-tailed test)

Alternative Hypothesis:

Increased training will not improve awareness of employee fatigue.

\section{MethodS}

Does lack of training affect employees' awareness of worker fatigue? Using quantitative design, 50 health and safety professionals from a variety of companies were selected from LinkedIn to participate in a survey based on their knowledge of fatigue awareness in the workplace. A cross section of American industries was chosen to give a comprehensive view. As shown in Table 1, there were 50 participants consisting of 40 men and 10 women with an average age of 37.5 years. All were tenured employees with 5 years of employment, and 49 were employed at the time of the survey. The instrument used was a Likert scale via the Survey Monkey platform. Small samples on the 5-point Likert scale gave us a broader range of answers. The aim of the study was to estimate how many companies have fatigue awareness programs, including training to enable employees to become more educated on the subject. The survey was developed to a rating scale of points from 1 to 5. The survey was published on LinkedIn, a professional website designed for networking with colleagues and people from other professional backgrounds. The survey started on November 6, 2020 and ran for 7 days. Participants were asked complete a short survey about "Fatigue in the workplace." No more guidance was given at that time unless the participants had questions. The surveys took 1 minute and 33 seconds on average to complete. There were 9 questions in total to evaluate the participants' theory on workplace fatigue.

\section{RESUlts}

\section{Survey Questions}

1. Does your employer train you on workplace fatigue?

2. Do you believe fatigue impacts workplace safety and production?

3. Should your employer incentivize you for completing workplace fatigue training?

4. Does your employer perform adequate training on workplace fatigue?

5. Should your employer offer resources to combat workplace fatigue?

6. Does getting proper rest help protect you from workplace fatigue?

7. Do you know the signs and symptoms of fatigue?

8. Would it be important to know the number of injuries companywide due to workplace fatigue?

9. Would knowing company profit lost due to fatigue interest you? 
Health Informatics - An International Journal (HIIJ) Vol.10, No.1, February 2021

\begin{tabular}{|c|c|c|c|c|c|c|c|}
\hline Questions & Total Participants & Strongly Agree $\%$ & Agree $\%$ & Undecided $\%$ & Disagree \% & Strongly Disagree $\%$ & Total \% \\
\hline 1 & 50 & 8 & 30 & 8 & 30 & 24 & 100 \\
\hline 2 & 50 & 25 & 22 & 1 & 0 & 2 & 100 \\
\hline 3 & 50 & 9 & 13 & 18 & 6 & 4 & 100 \\
\hline 4 & 50 & 3 & 10 & 6 & 22 & 9 & 100 \\
\hline 5 & 50 & 16 & 23 & 5 & 4 & 1 & 100 \\
\hline 6 & 50 & 19 & 27 & 3 & 0 & 0 & 100 \\
\hline 7 & 50 & 18 & 22 & 5 & 5 & 1 & 100 \\
\hline 8 & 50 & 21 & 22 & 5 & 1 & 1 & 100 \\
\hline 9 & 50 & 17 & 24 & 6 & 2 & 1 & 100 \\
\hline
\end{tabular}

Figure 1. Likert scale results based on agreeability

\begin{tabular}{|l|r|r|r|r|r|}
\hline \multicolumn{1}{|c|}{ SUMMARY } & & & & \\
\hline
\end{tabular}

Figure 2. One-tailed ANOVA test to find the F crit.

\section{AnALYSIS}

Although overall awareness was moderate, the analysis shows that employees seek facts on the topic of workplace fatigue awareness. It was determined that most companies do not provide their employees with training on workplace fatigue. Participants were undecided if they should be incentivized for being trained on fatigue. Training offered by employers was shown to be inadequate or non-existent. It was agreed that employers should offer resources to combat workplace fatigue. Participants agreed that getting proper rest helps protect them from workplace fatigue. Participants agreed they understand the signs and symptoms of fatigue. They found it important to know the number of injuries companywide due to workplace fatigue.

\section{CONCLUSION}

Based on the questions presented in the survey, we can conclude that fatigue awareness is high among employees, but training is needed to better educate them on workplace fatigue. It was also found that very few companies have developed guidelines and there is a lack of any type of incentive program for their employees. More studies are needed to better understand what direct training is needed to follow fatigue awareness policies. ANOVA is $95 \%$ confidence; we do not reject the null hypothesis and conclude that the average score it takes to process applications is 95\% confidence. No human research ethics were used to retrieve survey results.

\section{REFERENCES}

[1] Atkinson, W. (1999). Wake up! fighting fatigue in the workplace. Risk Management, 46(11), 10-22. Retrieved from https://franklin.captechu.edu:2074/docview/226992067?accountid=44888 
Health Informatics - An International Journal (HIIJ) Vol.10, No.1, February 2021

[2] Sawatzky, S. (2017). Worker fatigue: Understanding the risks in the workplace. Professional Safety, 62(11), 45-51. Retrieved from https://franklin.captechu.edu:2074/docview/1960314228?accountid=44888

[3] Ziebertz, C. M., Madelon L M van, H., Beckers, D. G. J., Hooftman, W. E., Kompier, M. A. J., \& Geurts, S. A. E. (2015). The relationship of on-call work with fatigue, work-home interference, and perceived performance difficulties. BioMed Research International, 2015 doi:http://franklin.captechu.edu:2123/10.1155/2015/643413

[4] R. A. Karasek, C. Brisson, N. Kawakami, I. Houtman, P. Bongers, and B. Amick, "The Job Content Questionnaire (JCQ): An instrument for internationally comparative assessments of psychosocial job characteristics," Journal of Occupational Health Psychology, vol.3, no.4, pp. 322-355, 1998.

[5] Sholihah, Q., \& Fauzia, R. (2014). Relationship work fatigue related to work stress on circadian rhythm night shift operator employee PT. Indonesia Bulk Terminal Kotabaru, South Kalimantan, Indonesia. The European Journal of Social \&Behavioural Sciences, 9(2), 1423-1430. Retrieved from https://franklin.captechu.edu:2074/docview/1534160210?accountid=44888

[6] Gross, S., Semmer, N. K., Meier, L. L., Kälin, W., Jacobshagen, N., \&Tschan, F. (2011). The effect of positive events at work on after-work fatigue: They matter most in face of adversity. Journal of Applied Psychology, 96(3), 654. Retrieved from https://franklin.captechu.edu:2074/docview/869627270?accountid=44888

[7] Sholihah, Q., Fauzia, R., \&Hafizhah, N. A. (2014). Occupational health and safety control of circadian rhythm disorders to work stress on night shift coal port workers. Advanced Science, $\begin{array}{llll}\text { Engineering and } \quad \text { Medicine, } & \text { 151-154. }\end{array}$ doi:http://franklin.captechu.edu:2123/10.1166/asem.2014.1467

[8] Stynen, D., Jansen, N. W. H., \& Kant, I. J. (2017). The impact of work-related and personal resources on older workers' fatigue, work enjoyment and retirement intentions over time. Ergonomics, 60(12), 1692-1707. doi:http://franklin.captechu.edu:2123/10.1080/00140139.2017.1334094

[9] Roach, G. D., Fletcher, A., \& Dawson, D. (2004). A model to predict work-related fatigue based on hours of work. Aviation, Space, and Environmental Medicine, 75(3), A61-A69. Retrieved from https://franklin.captechu.edu:2074/docview/28216630?accountid=44888

[10] Ahsberg, E., Gamberale, F., \& Gustafsson, K. (2000). Perceived fatigue after mental work: An experimental evaluation of a fatigue inventory. Ergonomics, 43(2), 252-268. Retrieved from https://franklin.captechu.edu:2074/docview/208937451 accountid=44888 